\title{
GCU
}

Glasgow Caledonian

University

University for the Common Good

\section{The influence of age, refractive error, visual demand and lighting conditions on accommodative ability in Malay children and adults}

Chen, Ai-Hong; Ahmed, Azmir; Kearney, Stephanie; Strang, Niall

Published in:

Graefe's Archive for Clinical and Experimental Ophthalmology

DOI:

$10.1007 / \mathrm{s} 00417-019-04405-z$

Publication date:

2019

Document Version

Author accepted manuscript

Link to publication in ResearchOnline

Citation for published version (Harvard):

Chen, A-H, Ahmed, A, Kearney, S \& Strang, N 2019, 'The influence of age, refractive error, visual demand and lighting conditions on accommodative ability in Malay children and adults', Graefe's Archive for Clinical and Experimental Ophthalmology, vol. 257, no. 9, pp. 1997-2004. https://doi.org/10.1007/s00417-019-04405-z

\section{General rights}

Copyright and moral rights for the publications made accessible in the public portal are retained by the authors and/or other copyright owners and it is a condition of accessing publications that users recognise and abide by the legal requirements associated with these rights.

Take down policy

If you believe that this document breaches copyright please view our takedown policy at https://edshare.gcu.ac.uk/id/eprint/5179 for details

of how to contact us. 
Title: The influence of age, refractive error, visual demand and lighting conditions on accommodative ability in Malay children and adults

\begin{abstract}
Purpose: Near work, accommodative inaccuracy and ambient lighting conditions have all been implicated in driving the myopic development mechanism. However, difference in accommodative responses with age and refractive error under different visual conditions remain unclear. This study explores differences in accommodative abilities and refractive error when exposed to differing ambient illumination and visual demands in Malay schoolchildren and adults.
\end{abstract}

Methods: Sixty young adults (21-25 years) and sixty school children (8-12 years) were recruited. Accommodative lag and accommodative fluctuations at far $(6 \mathrm{~m})$ and near $(25 \mathrm{~cm})$ were measured using the Grand Seiko WAM5500 open field autorefractor. The effect of mesopic room illumination on accommodation were also investigated. Results: Repeated measures ANOVA indicated that accommodative lag at far and near was significantly different in school children and young adults $(\mathrm{F}(1.219,35.354)=11.857, \mathrm{p}<0.05)$ with post hoc tests using the Bonferroni correction determined that at near, there was a greater lag in school children $(0.486 \pm 0.181 \mathrm{D})$ than young adults $(0.259 \pm 0.209 \mathrm{D}, \mathrm{p}<0.05)$. Repeated measures ANOVA also determined that accommodative lag differed statistically at near demands between non-myopic group and the myopic group in young adults and school children $(\mathrm{F}(3.107,31.431)=12.187, \mathrm{p}<0.05)$. Post hoc tests using the Bonferroni correction showed that accommodative lag at near was significantly greater in myopic school children $(0.655 \mathrm{D} \pm 0.198 \mathrm{D})$ compared with non-myopic school children $(0.202 \mathrm{D} \pm 0.141 \mathrm{D}, \mathrm{p}<0.05)$ and myopic young adults $(0.316 \mathrm{D} \pm 0.172 \mathrm{D}, \mathrm{p}<0.05)$, but no significant difference between myopic young adults $(0.316 \mathrm{D} \pm 0.172 \mathrm{D})$ and non- myopic young adults $(0.242 \mathrm{D}$ $\pm 0.126 \mathrm{D}, \mathrm{p}>0.05)$. Accommodative lag and fluctuations were greater in mesopic room conditions for all ages [all $\mathrm{p}<0.05]$.

Conclusion: Greater accommodative lag was found in myopes compared to emmetropes, school children compared to adults and in mesopic compared to photopic conditions. Accommodative fluctuations were greatest in myopes and in mesopic conditions. These results suggest that differences exist in the amount of blur experienced by myopes and non-myopes at different ages and in different lighting conditions.

Keywords: accommodation, myopia, lag of accommodation, illumination, children 


\section{Introduction}

Myopia is the most common type of refractive error affecting Malay school children [1,2]. The incidence increased with age (4.3\% at 7-8 years and $25.6 \%$ at $15-16$ years) [3]. Increasing trend of myopia prevalence in Malay was similar to other ethnicity [4]. Differing environments and lifestyles between countries such as the time spent outdoors and educational attainment might be the main contributing factors [5]. The prevalence of myopia is lower amongst Malay children living in Malaysia in comparison to children of the same ethnicity in Singapore [6]. Additionally, the prevalence of myopia in Chinese children living in Singapore is also different than children of the same ethnicity in Sydney [7]. Higher myopia prevalence among the Chinese in Hong Kong [8] compared to in the United States of America [9] could be influenced by different styles of upbringing, as traditionally parents in Asian countries were stern in raising their child particularly related to education. Greater magnitude of myopia was observed when higher educational level was attained [10] indicating a huge increase in myopic refractive error with demanding learning activities related to academic level. The high prevalent of myopia among Jewish male students in Orthodox school was attributed to the prolonged daily near work with variety of near target sizes [11]. The effect of environment on vision system had been the center of debates in myopia development, where various environmental factors such as near work, academic activity, outdoor physical activity, dietary intake and occupation were implicated [12]. Study on dopamine and ocular growth also suggested the link of lighting to myopia development [13]. However, among the factors, near work was reported to have the strongest influence to increase the risk for myopia development [14]. There was an association of myopia with less time spent outdoors, greater time spent on near work, closer working distance and higher intensity of near work [15-17]. The complex relationship between near work and accommodation was based on the notion that failure to compensate for retinal image defocus could lead to myopia development [18]. Environmental factors such demand and lighting conditions involved in the blur processing of retinal image defocus and were implicated to be part of mechanistic basis for the development of myopia [13]. This blur processing tangled stimulus-response function where accommodative inaccuracies could occur. Accommodative inaccuracies during near work may contribute to myopic growth by producing hyperopic defocus on the retina which might act as a stimulus for axial elongation $[19,20]$. An increase in accommodative demand resulted in an increase in accommodative microfluctuations under low luminance [21]. High demand and low lighting affected the retinal image clarity maintenance in relation to near work-accommodation-myopia development, in which more effort to accommodation was required to ensure in-focus target with the reduction in lighting level. Myopes demonstrated greater accommodative microfluctuations than emmetropes [21,22]. Myopes was claimed to have a greater depth of field and a higher threshold for retinal blur due to differences in neural innervation of accommodative control between refractive groups $[21,22]$.

There was still conflicting evidence in the mechanism. Study in adults reported greater accommodative lag in progressing myopes in comparison to stable myopes [23]. However, a large multi-ethnic study reported that accommodative lag was not associated with myopic progression which might suggest the contribution of ethnicity [24]. It is unknown if accommodative errors are associated with myopia in the Malay population [25]. Another study in children reported that accommodative lag occurred after myopic onset [26] as a consequence of myopic growth. Accommodative responses were more sluggish amongst myopic children when examining accommodative response curves [27]. The influence of age and refractive status on the involvement of 
accommodation inaccuracies in myopia development remained debatable and required further investigation. Due to the close association of near task, demand and lighting, it is important to explore differences in accommodative abilities and refractive error when exposed to differing ambient illumination and visual demands in Malay schoolchildren and adults.

\section{Materials and methods}

The same windowless experimental room $(9 \times 4.5 \times 3 \mathrm{~m}$ room $)$ was used for all participants to minimize technical error and exposure bias. The Konica Minolta Luxmeter CL-500A was used to measure and verify room illumination level which was set at approximately 500 lux using a fluorescein lamp (cool colour light 6500K) as recommended for vision assessment illumination [28]. This is in accordance with the Illuminating Engineering Society (IES) as the standardized illumination for in-door working and general areas [29]. Ethical approval and informed consent were obtained prior to data collection and the study adhered to the Declaration of Helsinki.

Sixty Malay young adults (aged 21-25 years) and sixty Malay school children (aged 8-12 years) with best corrected distance visual acuity of 0.0 unit $\log$ MAR or better and with no known ocular pathology were recruited. Non-cycloplegic distance refraction was completed before each test session by a qualified optometrist using binocular subjective refraction to an end- point best visual acuity of minimum minus. None of the participants exhibited astigmatism or anisometropia of greater than $1.00 \mathrm{D}$. Myopia was defined as a spherical equivalent refraction (SER) of $-0.75 \mathrm{D}$ or greater [22]. A total of 30 myopic and 30 non myopic young adults, in addition to 30 myopic and 30 non myopic school children were measured in this study. To avoid experimental bias the order of the assigned procedures was randomised using the Microsoft Excel random function and participants were single blinded.

Prior to measures, participants were provided with 5 minutes of dark adaptation to relax their accommodation [30]. Participants were then directed into the experimental room for five-minutes of light adaption while maintaining distance fixation. Although all participants were not habitual contact lenses wearers, to minimize magnification effects, all myopes with a SER of $-0.75 \mathrm{D}$ or greater were corrected with daily disposable contact lens (1-Day Acuvue (Johnson \& Johnson; Malaysia). The appropriate base curve was chosen ( $8.5 \mathrm{~mm}$ or $9.0 \mathrm{~mm}$ ) and $20 \mathrm{mins}$ for contact lens adaptation was provided. Contact lens wear could promote tears flow, ocular dryness condition and slight acceptable contact lens movement. However, all related contact lens wear conditions did not affect the visual stability as soft contact lenses were used in this study. Previous researchers discovered that thin soft contact lenses had no impact on the magnitude or frequency characteristics of microfluctuations of accommodation response [31]. Visits were completed on two different days to allow for a wash out period and they were completed at the same time of day to minimise diurnal effects.

The accommodative response was measured objectively using a binocular free-space open field autorefractor (WAM-5500, Grand Seiko Co., Ltd.; Japan) which was proven reliable for dynamic measurement [32]. A $0.0 \log M A R$ letter on a high contrast ETDRS $\log M A R$ chart at $6 \mathrm{~m}$ at eye level was used as the distance fixation target. This created $0.17 \mathrm{D}$ of accommodative demand. A $0.0 \log$ Mar letter from a MNREAD chart at $25 \mathrm{~cm}$ was used as a near fixation target creating 4.00D of accommodative demand. Previous studies comparing accommodative responses in myopes and emmetropes report that a statistical difference in accommodative lag is detectable using a stimulus of $4 \mathrm{D}$ [33]. As measurement was done with room light of 500 lux, the procedure was 
repeated without room light of 10 lux under mesopic condition. This was achieved by extinguishing lights inside the experimental room and narrowly opening the room door to allow minimal ambient light from outside to allow mobility of the examiner when completing measures. Vertex distance compensation of $12 \mathrm{~mm}$ was set in the autorefractor for all measurements. The reference points for both accommodation stimulus and response were measured at spectacle plane. Objective refractive state measures were recorded using WCS-1 software using a sampling frequency of $5 \mathrm{~Hz}$. Readings were taken continuously, equating to at least two measurements per second, and imported to Microsoft Excel. A minimum of 120 readings for each participant were captured automatically. Measurements obtained during a blink and outliers were excluded. An under-blink reading was defined as a blank portion of the measurement or a spike in measures taken during blinking with a value greater than the mean. Both the under-blink reading and extreme data were considered as noise. On average, the under-blink reading accounted for less than $10 \%$ of data being removed during each trace.

Instruction to the participants was given according to the standardized clinical measurement procedures for accommodation response which was to keep the targets clear and single all the time [34]. Furthermore, the targets were located at the viewing center to ensure steady fixation from the participants [35]. The fixation was continuously monitored to ensure alignment to the autorefractor measurement system and maintenance of accommodation effort from the participants to the targets. If the fixation became unsteady, the participants were asked to read out the targets periodically to control variation in accommodative response due to the wavering eye which accounted to less than $10 \%$ occurrence in the continuous measurement. By subtracting the accommodative response value from the accommodative stimulus value, the response was expressed as a lag or lead of accommodation [36]. To further explore accommodative ability, the fluctuation in the accommodative response was also investigated. Due to the continuous nature of the recording system, the root mean square (RMS) was reported [37].

\section{Statistical analysis}

In this study, accommodative abilities of the same participants were repeatedly measured under different conditions. Thus, repeated measure one-way analysis of variance (ANOVA) was used to determine the statistical difference in the accommodative ability between young adults and school children at $6 \mathrm{~m}$ and $25 \mathrm{~cm}$ and between myopes and non-myopes in each age group at $25 \mathrm{~cm}$. The repeated measure ANOVA was also used to determine the effect of room illumination on accommodative responses in each age group. Post hoc test using Bonferroni correction was to establish the statistical level of pair wise comparison while reducing the possibility of type I errors when multiple pair wise tests were performed. All statistical tests used a statistical significance level of $\mathrm{p}<0.05$.

\section{Results}

Participant information is summarised in Table 1. 
Table 1 about here

Accommodative lag was evident in both the young adults and the school children in response to far and near accommodative stimuli (Fig. 1). Repeated measures ANOVA determined that accommodative lag differed statistically significantly between the far and near demands $(F(1.219,35.354)=11.857, p<0.05)$ between young adults $(0.101 \pm 0.196 \mathrm{D}$ and $0.259 \pm 0.209 \mathrm{D}$, respectively) and school children $(0.112 \pm 0.185 \mathrm{D}$ and $0.486 \pm$ $0.181 \mathrm{D}$, respectively). Post hoc tests using the Bonferroni correction revealed that the lag of accommodation at near was significantly greater in children compared with adults $(\mathrm{p}<0.05)$, but no significant difference in the lag of accommodation at far between school children and young adults $(\mathrm{p}>0.05)$. Additionally, the error bars relating to accommodative lag at near were greater in the school children indicating greater variability.

Fig. 1 about here

As for the refractive groups, repeated measures ANOVA determined that accommodative lag differed statistically at near demands $(\mathrm{F}(3.107,31.431)=12.187, \mathrm{p}<0.05)$ between non-myopic group and the myopic group in young adults $(0.242 \mathrm{D} \pm 0.126 \mathrm{D}$ and $0.316 \mathrm{D} \pm 0.172 \mathrm{D}$, respectively) and in school children $(0.202 \mathrm{D} \pm$ $0.141 \mathrm{D}$ and $0.655 \mathrm{D} \pm 0.198 \mathrm{D}$, respectively), illustrated in Fig. 2. Post hoc tests using the Bonferroni correction revealed that the lag of accommodation at near was significantly greater in myopic school children compared with non-myopic school children $(\mathrm{p}<0.05)$ and myopic young adults $(\mathrm{p}<0.05)$. However, post hoc analysis determined that the was no significant difference in the lag of accommodation at near between myopic young adults and non- myopic young adults $(\mathrm{p}>0.05)$.

Fig. 2 about here

Repeated measures ANOVA determined that accommodative lag differed statistically significantly at near $(\mathrm{F}(1.005,29.145)=56.516, \mathrm{p}<0.05)$ between mesopic condition and high room illumination condition in young adults $(0.675 \mathrm{D} \pm 0.212 \mathrm{D}$ and $0.259 \mathrm{D} \pm 0.177 \mathrm{D}$, respectively) and in school children $(0.944 \mathrm{D} \pm 0.238$ $\mathrm{D}$ and $0.522 \mathrm{D} \pm 0.181 \mathrm{D}$, respectively). Accommodative lag increased in mesopic conditions compared with high room illumination conditions. Post hoc tests using the Bonferroni correction revealed that the lag of accommodation was significantly greater among school children in mesopic conditions in comparison to high room illumination condition in school children $(\mathrm{p}<0.05)$, shown in Fig. 3 and mesopic condition in young adults 
$(p<0.05)$. As post hoc analysis tested paired comparison, further statistical test on accommodative fluctuations was done using paired t-test. In the school children, accommodative fluctuations increased in mesopic room conditions [ $\mathrm{t}=-6.938, \mathrm{p}<0.05$ ] (high illumination: $0.263 \mathrm{D} \pm 0.109 \mathrm{D}$, mesopic illumination $0.356 \mathrm{D} \pm 0.160 \mathrm{D}$ ).

Fig. 3 about here

There was no significant difference in the fluctuation of accommodation at $6 \mathrm{~m}$ between the young adults $(0.163 \pm 0.088 \mathrm{D})$ and school children $(0.198 \pm 0.096 \mathrm{D})[\mathrm{t}=6.128, \mathrm{p}>0.05]$. There was also no significant difference in the fluctuation of accommodation between the young adults $(0.247 \pm 0.108 \mathrm{D})$ and the school children $(0.279 \pm 0.109 \mathrm{D})$ at near $[\mathrm{t}=1.604, \mathrm{p}>0.05]$.

In the young adults, the fluctuation of accommodation was more stable among the non-myopic group $(0.194 \pm 0.091 \mathrm{D})$ than the myopic group $(0.300 \pm 0.990 \mathrm{D})[\mathrm{t}=-4.328, \mathrm{p}<0.05]$. In the school children, the fluctuation of accommodation was significantly greater in the myopic group $(0.329 \pm 1.011 \mathrm{D})$ than the nonmyopic group $(0.229 \pm 0.095 \mathrm{D})$ [ $\mathrm{t}=-3.904, \mathrm{p}<0.05]$.

\section{Discussion}

This study in a Malay population reports that school children exhibit greater accommodative lag and greater accommodative fluctuations at near than young adults. This finding is consistent with previous reports that several visual statuses including accommodation and convergence continue to stabilise throughout the early school years [38-41]. Myopic Malay school children demonstrated accommodative lag up to three times greater than non-myopic Malay school children. This association was not significant in the young adult group which may indicate that accommodative deficiencies are eliminated with increasing age and refractive stability.

A large multi-ethnic study reported that Asian myopic children exhibited greater accommodative lag than African-American, White and Hispanic myopic children [26], correlating with a higher prevalence of myopia amongst Asian children. The mechanism resulting in accommodative lag may be attributed to mechanical differences between the myopic and non-myopic eye. Mutti et al [42] speculate that accommodative deficits may arise from an increase in tension in the crystalline lens within the large myopic eye creating resistance to accommodation, increasing the effort required to accommodate resulting in accommodative lag. Eventual resistance to axial elongation within the lens may result in a transfer of tension to the choroid and choroidal resistance also impeding accommodation. Seidel et al. [43] report that more time was required to change focus from distance to near, linked to a reduced ability to relax accommodation, in myopic individuals. The authors suggest that this finding may be attributed to differences in the properties of the crystalline lens and ciliary body between myopes and non-myopes. A thicker ciliary body has been reported in myopic children which may contribute to accommodative inaccuracies including accommodative lag [44]. 
Myopes demonstrated greater accommodative fluctuations than non-myopes in agreement with previous research [21]. Day et al [21] suggest that greater accommodative microfluctuations in myopes arise from a larger depth of focus, defined as the maximum defocus applied to a focused image without subjective detection [45]. This may occur due to differences in the visual feedback and blur adaptation system between refractive groups. Literature also reports that myopes demonstrate greater blur adaptation when removing their refractive correction [46] and a greater objective blur threshold [43]. As myopes may be able to tolerate greater levels of defocus than non-myopes, the myopic retina may be exposed to greater amounts of hyperopic defocus for longer periods of time than their non-myopic counterparts, promoting myopic growth [47].

Accommodative lag and accommodative fluctuations were also greater in mesopic light as reported elsewhere [21]. Wide bandwidths of illumination allow the visual system to focus more accurately and to detect blur [48] thereby improving the accommodative response. This study supports the use of accommodative fluctuation as a useful assessment of accommodative function in the investigation of myopia and accommodative errors. This may aid in identifying those who may benefit from accommodative intervention and exercise.

Myopic interventions designed to negate peripheral hyperopic defocus such as multifocal and bifocal soft contact lenses and orthokeratology are recommended by eye care practitioners [49]. These interventions may reduce myopic progression by up to $50 \%$ [50]. The influence of multifocal contacts lens on accommodative ability in children with accommodative inaccuracies is unknown [51]. Further research is required to explore accommodative responses in young children wearing multifocal lenses to determine how accommodative fluctuation and accommodative lag are affected by such treatments.

Our study findings were unique as accommodation responding abilities in four conditions were measured collectively via objective measurement and comparable sample size. Previous studies have looked into the environmental effect on accommodation and myopia, such as accommodation demand and luminance, only in adults [21-23]. Unfortunately, simultaneous investigation on the demand, illumination and refractive factors using the same measurement techniques to compare between young adults and school children was unavailable. Our study used the same setting, target, measurement protocol and demand for direct comparison to minimize the confounding factors due to subjects and measurement techniques variation. Those variations were among the hindrances for direct comparison of previous investigations on environmental effects as different target types and experimental settings were used in each study [22,23]. Our study could provide more comprehensive understanding on accommodation and myopia as the settings and target types was controlled and made compatible between young adults and school children.

One of the limitation in our study was lacking of data on pupil size. All measurements were conducted under natural pupil size. which raised a question on pupil size effect on our findings. A study by Charman and Radhakrishnan in 2009 [52] on the relationship between pupil size and age had outlined a regression-linear formula between the two parameters [pupil $=(-0.0836 \mathrm{x}$ age $)+7.5788$ ] The pupil size decreased with age, indicating a bigger pupil size in children as compared to adults. Using this formula, the estimated pupil size in young children and young adults in our study was $6.69 \mathrm{~mm}$ and $5.80 \mathrm{~mm}$ respectively. The difference of pupil size between the two age groups was about $1.19 \mathrm{~mm}$. If the difference of $3.04 \mathrm{~mm}$ in pupil size was reported to account to a $0.05 \mathrm{D}$ of accommodation response change for the same far demand [53], hypothetically the pupil size of $1.19 \mathrm{~mm}$ difference between young adults and school children in our study might account for an accommodation response difference of $0.02 \mathrm{D}$. This slight variation was unlikely to change the results. The 
relationship between pupil size and refractive was also investigated by Charman and Radhakrishnan [52] and they outlined a regression-linear formula between the two parameters [pupil $=(-0.0268 \times$ mean-sphere errors $)+$ 5.5201]. We try to estimate the variation might cause by pupil size in our subjects due to refractive error difference. The estimated pupil size in myopic and non-myopic young adults in our study were $5.60 \mathrm{~mm}$ and $5.52 \mathrm{~mm}$ respectively. The difference of pupil size between myopic and non-myopic young adults was approximately 0.08 $\mathrm{mm}$. Hypothetically, pupil size of $0.08 \mathrm{~mm}$ difference between myopic and non-myopic young adults in our study might contribute to an accommodation response difference of $0.001 \mathrm{D}$. This slight variation was unlikely to alter the outcome. Similarly, the estimated pupil size in myopic and non-myopic school children in our study were 5.59 $\mathrm{mm}$ and $5.52 \mathrm{~mm}$ respectively. The difference of pupil size between myopic and non-myopic school children was approximately $0.07 \mathrm{~mm}$. Hypothetically, pupil size of $0.07 \mathrm{~mm}$ difference between myopic and non-myopic school children in our study might contribute to an accommodation response difference of $0.001 \mathrm{D}$. The difference in lag between myopic and non-myopic school children of $0.453 \mathrm{D}$ was significant $(\mathrm{F}(3.107,31.431)=12.187, \mathrm{p}$ $<0.05)$. By taking into consideration a possible difference of $0.001 \mathrm{D}$ due to pupil size estimation, the difference in lag between myopic and non-myopic school children would become $0.454 \mathrm{D}$. A difference of $0.001 \mathrm{D}$ due to pupil size was unlikely to affect the significant different findings in refractive groups among children. The pupil size had been reported to decrease when the demand increased from 0 to $6 \mathrm{D}$ due to near triad [54]. The relationship between the two tabulated parameters could be described by a regression-linear formula [pupil $=-0.1318$ (demand) +5.6839 ]. Using the formula, the estimated pupil size at far and near demand in our study were $5.68 \mathrm{~mm}$ and 5.16 $\mathrm{mm}$ respectively. Hypothetically, pupil size of $0.52 \mathrm{~mm}$ difference between far and near demand in our subjects might contribute to an accommodation response difference of $0.047 \mathrm{D}$. A difference of less than $0.05 \mathrm{D}$ due to pupil size was unlikely to affect for the original findings. The pupil size was reported to decrease when the lighting increased [55]. The pupil size decreased from $5.40 \mathrm{~mm}$ under the lighting of 2 lux to $3.54 \mathrm{~mm}$ under 550 lux. The relationship between the two tabulated parameters could be predicted by a regression-linear formula [pupil = 0.0033 (lighting in lux) +5.4027 ]. Using the formula, the estimated pupil size under mesopic (10 lux) and photopic (500 lux) lighting in our study were $5.37 \mathrm{~mm}$ and $3.75 \mathrm{~mm}$ respectively. Hypothetically, pupil size of $1.62 \mathrm{~mm}$ difference between mesopic and photopic lighting in our subjects might contribute to an accommodation response difference of $0.03 \mathrm{D}$. A difference of less than $0.05 \mathrm{D}$ due to pupil size was unlikely to affect the outcomes. The accommodation variation possibly caused by pupil size in our study (ranged from 0.001 to $0.02 \mathrm{D}$ ) was unlikely to account or affect the conclusion of this study. However, our explanation did not rule out the possible contribution of pupil size in myopia development as depicted in previous studies [56,57]. Undeniable about the importance of pupil size data in addressing the issues on myopes with reduced sensitivity to blur when compared with non-myopes which could be accounted from the pupil size difference $[58,59]$. Ocular aberration due to the change in pupil size with increasing stimulus demand had been reported to be no difference between myopes and non-myopes [60]. The image blurriness due to the lag of accommodation did not hinder from performing visual task as depth of focus could ameliorate the blur condition [61,62]. However, when the lag of accommodation increased especially among myopes [63], the pupil might not constrict proportionately in tandem with the lag increment to lessen the blur exposure. Thus, myopes might still be susceptible to the near work-accommodation interaction which was one of the factors for myopia development. 


\section{Conclusion}

Greater accommodative lag and greater accommodative fluctuations were associated with myopia in Malay school children. Accommodative lag and accommodative fluctuations were greater in school children in comparison to young adults. These results may indicate differences in the amount of blur experienced by individuals of different ages and between refractive groups.

Acknowledgement Special thanks to Prof. Edward Mallen (University of Bradford, UK) and Saiful Azlan Rosli (iROViS, UiTM) for their technical assistance in Grand Seiko and lighting setup.

\section{Compliance with ethical standards}

All procedures in this research adhered to the ethical standards of the institutional research committee in accordance with the 1964 Helsinki declaration.

Informed consent Informed consent was obtained from all participants and the legal guardians in the study SF0452) under the Ministry of Science, Technology and Innovation of Malaysia.

Conflict of interest None of the authors has any proprietary interests or conflicts of interest related to this submission.

\section{References}

1. Hashim SE, Tan HK, Wan-Hazabbah WH, Ibrahim M (2008) Prevalence of refractive error in Malay primary school children in suburban area of Kota Bharu, Kelantan, Malaysia. Ann Acad Med Singapore.;37(11):940946.

2. Ramlee A, Pin GP (2012) Ocular biometric measurements in emmetropic and myopic Malaysian children a population-based study. Med J Malaysia.;67(5):497-502.

3. Garner LF, Chung KM, Grosvenor TP, Mohidin M (1990) Ocular dimension and refractive power in Malay and Malanesian children. Ophthal Physiol Opt.;10: 234-238.

4. Goh PP, Abqariyah Y, Pokharel GP, Ellwein LB (2005) Refractive error and visual impairment in schoolage children in Gombak District, Malaysia. Ophthalmology.;112(4):678-685. 
5. Rose KA, Morgan IG, Ip J, Kifley A, Huynh S, Smith W, Mitchell P (2008) Outdoor activity reduces the prevalence of myopia in children. Ophthalmology.;115(8):1279-1285.

6. Saw SM, Goh PP, Cheng A, Shankar A, Tan DT, Ellwein LB (2006) Ethnicity-specific prevalences of refractive errors vary in Asian children in neighbouring Malaysia and Singapore. $\mathrm{Br} \mathrm{J}$ Ophthalmol.;90(10):1230-1235.

7. Rose KA, Morgan IG, Smith W, Burlutsky G, Mitchell P, Saw S (2008) Myopia, lifestyle, and schooling in students of Chinese ethnicity in Singapore and Sydney. Arch Ophthalmol.;126(4):527-530.

8. Lam CS, Goldschmidt E, Edwards MH (2004) Prevalence of myopia in local and international schools in Hong Kong. Optom Vision Sci.;81(5):317-22.

9. Kleinstein RN, Jones LA, Hullett S, Kwon S, Lee RJ, Friedman NE, Manny RE, Mutti DO, Julie AY, Zadnik K (2003) Refractive error and ethnicity in children. Arch Ophthalmol.;121(8):1141-1147.

10. Saw SM, Wu HM, Seet B, Wong TY, Yap E, Chia KS, Stone RA, Lee L. (2001) Academic achievement, close up work parameters, and myopia in Singapore military conscripts. Br J Ophthalmol.; 85(7): 855-860.

11. Zylbermann R, Landau D, Berson D (1993) The influence of study habits on myopia in Jewish teenagers. J Pediatr Ophthalmol Strabismus.; 30(5): 319-322.

12. Goldschmidt E, Jacobsen N (2014) Genetic and environmental effects on myopia development and progression. Eye.;28(2):126-133.

13. Chakraborty R, Ostrin LA, Nickla DL, Iuvone PM, Pardue MT, Stone RA (2018) Circadian rhythms, refractive development, and myopia. Ophthalmic Physiol Opt.;38(3):217-245.

14. Saw SM, Chua WH, Hong CY (2002). Near-work in early-onset myopia. Invest Ophthalmol Vis Sci.:43(2), 332-339.

15. Ip JM., Saw S, Rose KA, Morgan IG, Kifley A, Wang JJ, Mitchell P (2008) Role of near work in myopia: Findings in a sample of Australian school children. Invest Ophthalmol Vis Sci.;49(7):2903-2910.

16. Kinge B, Midelfart A, Jacobsen G, Rystad J (2000) The influence of nearwork on development of myopia among university students. A three-year longitudinal study among engineering students in Norway. Acta Ophthalmologica.;78(1):26-29.

17. Lin Z, Vasudevan B, Mao GY, Ciuffreda KJ, Jhanji V, Li XX, Zhou HJ, Wang NL, Liang YB (2016) The influence of near work on myopic refractive change in urban students in Beijing: a three-year follow-up report. Graefes Arch Clin Exp Ophthalmol.;254(11):2247-2255.

18. Hung GK, Ciuffreda KJ (2007) Incremental retinal-defocus theory of myopia development-schematic analysis and computer simulation. Comput Biol Med.;37(7):930-946.

19. Flitcroft DI (1998) A model of the contribution of oculomotor and optical factors to emmetropization and myopia. Vision Res.;38(19):2869-2879.

20. Norton T (1999) Animal models of myopia: Learning how vision controls the size of the eye. ILAR J.;40(2):59-77. 
21. Day M, Seidel D, Gray LS, Strang NC (2009) The effect of modulating ocular depth of focus upon accommodation microfluctuations in myopic and emmetropic subjects. Vision Res.;49(2):211-218.

22. Day M, Strang N, Seidel D, Gray L, Mallen EA (2006) Refractive group differences in accommodation microfluctuations with changing accommodation stimulus. Ophthalmic Physiol Opt.;26:88-96.

23. Abbott ML, Schmid KL, Strang NC (1998) Differences in the accommodation stimulus response curves of adult myopes and emmetropes. Ophthalmic Physiol Opt.;18(1):13-20.

24. Berntsen DA, Sinnott LT, Mutti DO, Zadnik K (2011) Accommodative lag and juvenile-onset myopia progression in children wearing refractive correction. Vision Res.;51(9):1039-1046.

25. Chen AH, Abidin AH (2002) Vergence and accommodation system in Malay primary school children. Malays J Med Sci.;9(1):9-15.

26. Mutti DO, Mitchell GL, Hayes JR, Jones LA, Moeschberger ML, Cotter SA, Kleinstein RN, Manny RE, Twelker JD, Zadnik K (2006) Accommodative lag before and after the onset of myopia. Invest Ophthalmol Vis.;47(3):837-846.

27. Yeo A, Kang K, Tang W (2006) Accommodative stimulus response curve of emmetropes and myopes. Ann Acad Med Singapore.;35(12):868-874.

28. Tidbury LP, Czanner G, Newsham D (2016) Fiat Lux: the effect of illuminance on acuity testing. Graefes Arch Clin Exp Ophthalmol.;254(6):1091-1097.

29. Kaufman JE, Christensen JF (1972) IES lighting handbook: The standard lighting guide. Illuminating Engineering Society.

30. Borsting E, Tosha C, Chase C, Ridder III WH (2010) Measuring near induced transient myopia in college students with visual discomfort. Optom Vis Sci.;87:760.

31. Day M, Strang NC, Seidel D, Gray LS (2008) Effect of contact lenses on measurement of the accommodation microfluctuations. Ophthalmic Physiol Opt.;28(1):91-95.

32. Lin Z, Vasudevan B, Zhang YC, Qiao LY, Liang YB, Wang NL, Ciuffreda KJ (2012) Reproducibility of nearwork-induced transient myopia measurements using the WAM-5500 autorefractor in its dynamic mode. Graefes Arch Clin Exp Ophthalmol.;250(10):1477-1483.

33. McBrien NA, Millodot M (1986) The effect of refractive error on the accommodative response gradient. Ophthalmic Physiol Opt.;6:145-149.

34. Sreenivasan V, Irving EL, Bobier WR (2014) Can current models of accommodation and vergence predict accommodative behavior in myopic children? Vision Res.;101:51-61.

35. Yeo AC, Atchison DA, Schmid KL (2013) Children's accommodation during reading of Chinese and English texts. Optom Vis Sci.;90(2):156-163.

36. Atchison DA, Varnas SR (2017) Accommodation stimulus and response determinations with autorefractors. Ophthalmic Physiol Opt.;37(1):96-104. 
37. Monticone PP, Menozzi M (2011) A review on methods used to record and analyze microfluctuations of the accommodation in the human eye. J Eur Opt Soc.;6:1103.

38. Dobson V, Quinn GE, Siatkowski RM, Baker JD, Hardy RJ, Reynolds JD, Trese MT, Tung B (1999) Agreement between grating acuity at age 1 year and Snellen acuity at age 5.5 years in the preterm child. cryotherapy for retinopathy of prematurity cooperative group. Invest Ophthalmol Vis.;40(2):496-503.

39. Corchuelo V, Pulgarín JD, Dolmetsch AM (2015) Ocular motility in children between ages 7 and 15 . In VI Latin American Congress on Biomedical Engineering CLAIB 2014, Paraná, Argentina 29, 30 \& 31 October 2014:95-98. Springer, Cham.

40. Chen AH, O'Leary DJ, Howell ER (2000) Near visual function in young children. part I: Near point of convergence. part II: Amplitude of accommodation. part III: Near heterophoria. Ophthalmic Physiol Opt.;20(3):185-198.

41. Benzoni JA, Rosenfield M (2012) Clinical amplitude of accommodation in children between 5 and 10 years of age. Optom Vis Dev.;43(3):109-114.

42. Mutti DO, Jones LA, Moeschberger ML, Zadnik K (2000) AC/A ratio, age, and refractive error in children. Invest Ophthalmol Vis Sci.;41:2469-2478.

43. Seidel D, Gray LS, Heron G (2003) Retinotopic accommodation responses in myopia. Invest Ophthalmol Vis Sci.;44(3):1035-1041.

44. Bailey MD, Sinnott LT, Mutti DO (2008) Ciliary body thickness and refractive error in children. Invest Ophthalmol Vis Sci.;49(10):4353-4360.

45. Rabbetts RB (1998) Ocular aberrations. In: Butterworth-Heinemann (ed) Clinical Visual Optics. 3rd edn. Oxford, UK, pp 288-289.

46. Rosenfield M, Hong SE, George S (2004) Blur adaptation in myopes. Optom Vis Sci.;81(9):657-662.

47. Cufflin M, Mankowska A, Mallen E. (2007) Effect of blur adaptation on blur sensitivity and discrimination in emmetropes and myopes. Invest Ophthalmol Vis Sci.;48(6):2932-2939.

48. Aggarwala KR, Kruger ES, Mathews S, Kruger PB (1995) Spectral bandwidth and ocular accommodation. J Opt Soc Am.;12(3):450-455.

49. Zloto O, Wygnanski-Jaffe T, Farzavandi SK, Gomez-de-Liaño R, Sprunger DT, Mezer E (2018) Current trends among pediatric ophthalmologists to decrease myopia progression-an international perspective. Graefes Arch Clin Exp Ophthalmol.;256(12):2457-2466.

50. Walline JJ (2016) Myopia control: A review. Eye Contact Lens.;42(1):3-8.

51. Gong CR, Troilo D, Richdale K (2017) Accommodation and phoria in children wearing multifocal contact lenses. Optom Vis Sci.;94(3):353-360. 
52. Charman WN, Radhakrishnan H (2009) Accommodation, pupil diameter and myopia. Ophthalmic Physiol Opt.;29(1):72-79.

53. Buehren T, Collins MJ (2006) Accommodation stimulus-response function and retinal image quality. Vision Res.;46(10):1633-1645.

54. Bernal-Molina P, Montés-Micó R, Legras R, López-Gil N (2014) Depth-of-field of the accommodating eye. Optom Vis Sci.;91(10):1208-1214.

55. Maqsood F (2017) Effects of varying light conditions and refractive error on pupil size. Cogent Med.;1;4(1):1338824.

56. Chen Z, Niu L, Xue F, Qu X, Zhou Z, Zhou X, Chu R (2012) Impact of pupil diameter on axial growth in orthokeratology. Optom Vis Sci.;89(11):1636-1640.

57. Guillon M, Dumbleton K, Theodoratos P, Gobbe M, Wooley CB, Moody K. (2016) The effects of age, refractive status, and luminance on pupil size. Optom Vis Sci.;93(9):1093.

58. Kasthurirangan S, Glasser A (2006) Age related changes in the characteristics of the near pupil response. Vis Research.; 46(8-9):1393-1403.

59. He JC, Sun P, Held R, Thorn F, Sun X, Gwiazda JE (2002). Wavefront aberrations in eyes of emmetropic and moderately myopic school children and young adults. Vision Res.;42(8):1063-1070.

60. Hazel CA, Cox MJ, Strang NC (2003) Wavefront aberration and its relationship to the accommodative stimulus-response function in myopic subjects. Optom Vis Sci.;80(2):151-158.

61. Day M, Seidel D, Gray LS, Strang NC (2009) The effect of modulating ocular depth of focus upon accommodation microfluctuations in myopic and emmetropic subjects. Vision Res.;49(2):211-218.

62. Lopez- Gil N, Martin J, Liu T, Bradley A, Díaz- Muñoz D, Thibos LN (2013) Retinal image quality during accommodation. Ophthalmic Physiol Opt.;33(4):497-507.

63. Gwiazda J, Thorn F, Bauer J, Held R (1993) Myopic children show insufficient accommodative response to blur. Invest Ophthalm Vis Sci., 34(3):690-694 
Table Submission

Table 1 Participant information: age and spherical equivalent refraction (SER)

\begin{tabular}{lll}
\hline Participant & Mean & Standard deviation \\
\hline Age in years & & \\
Adults & 21.28 years & \pm 0.99 years \\
School children & 10.65 years & \pm 0.61 years \\
\hline SER (Dioptres (D)) & & \\
Non-myopic young adults & RE: $+0.04 \mathrm{D}$ & $\pm 0.19 \mathrm{D}$ \\
& LE: $-0.10 \mathrm{D}$ & $\pm 0.26 \mathrm{D}$ \\
Myopic young adults & RE: $-3.01 \mathrm{D}$ & $\pm 1.96 \mathrm{D}$ \\
& LE: $-3.00 \mathrm{D}$ & $\pm 1.99 \mathrm{D}$ \\
Non-myopic school children & RE: $-0.06 \mathrm{D}$ & $\pm 0.15 \mathrm{D}$ \\
& LE: $-0.02 \mathrm{D}$ & $\pm 0.10 \mathrm{D}$ \\
Myopic school children & RE: $-2.46 \mathrm{D}$ & $\pm 1.70 \mathrm{D}$ \\
& LE: $-2.36 \mathrm{D}$ & $\pm 1.59 \mathrm{D}$ \\
\hline
\end{tabular}




\section{Electronic Figure Submission}

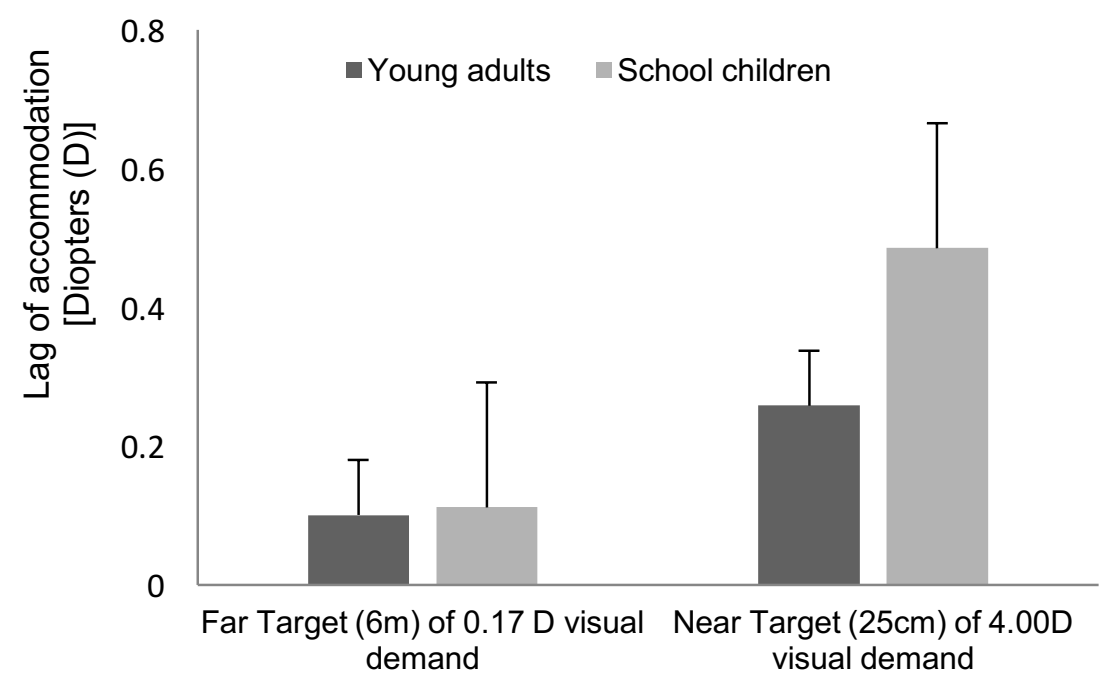

Fig. 1 Age effect (young adults versus school children) and visual demand effect (far versus near) on the lag of accommodation. 


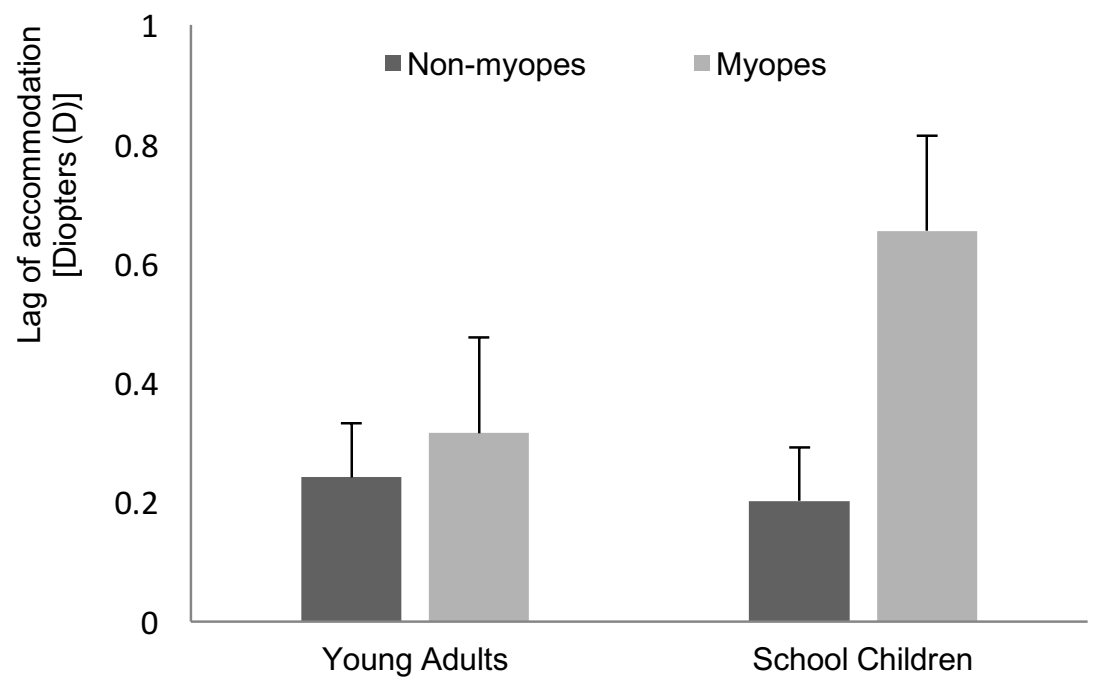

Fig. 2 Comparison of the lag of accommodation between the non-myopic group and the myopic group among young adults and school children exposed to a near visual demand of 4D. 


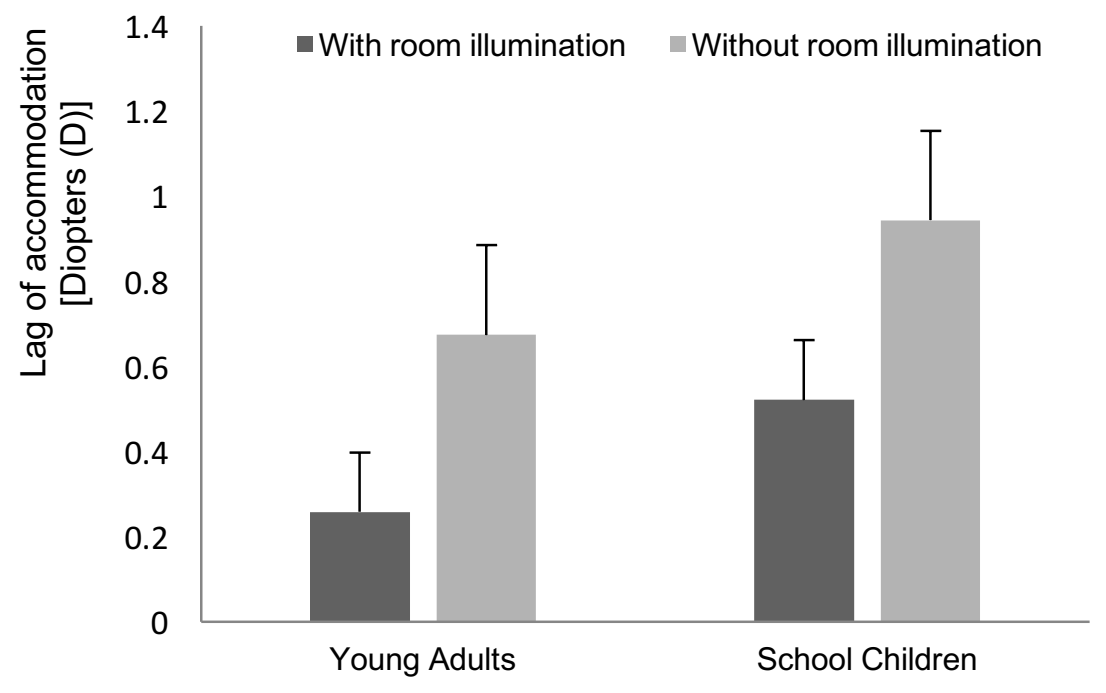

Fig. 3 Comparison of the lag of accommodation with and without room illumination among young adults and school children exposed to a near visual demand of 4D. 